\title{
An optimized protocol for purification of functional islets of Langerhans
}

\author{
Youakim Saliba ${ }^{1}$, Jules-Joel Bakhos ${ }^{1}$, Tarek Itani $^{2}$ and Nassim Farès ${ }^{1}$
}

Islets of Langerhans and $\beta$-cell isolation constitute routinely used cell models for diabetic research, and refining islet isolation protocols and cell quality assessment is a high priority. Numerous protocols have been published describing isolate of islets, but often rigorous and systematic assessment of their integrity is lacking. Herein, we propose a new protocol for optimal generation of islets. Pancreases from mice and rats were excised and digested using a low-activity collagenase solution and islets were then purified by a series of sedimentations and a Percoll gradient. Islets were maintained in culture for 5 days, during which viability, pro/antiapoptotic, and islet-specific genes, glucose-stimulated calcium entry, glucose uptake, and insulin secretion were assessed. The commonly used islet isolation technique by collagenase injection through the common bile duct (CBD) was also performed and compared with the present approach. This new protocol produced islets that retained a healthy status as demonstrated by the yield of stable living cells. Furthermore, calcium oscillation, glucose uptake, and insulin secretion remained intact in the islet cultures. This was reproducible when many rodent species were used, and neither sex nor age affected the cells behavior. When compared with the CBD technique, islet physiology was similar. Finally, this approach was used to uncover new ion channel candidates implicated in insulin secretion. In conclusion, this study outlines an efficient protocol for islet preparation that may support research into new therapeutic targets in diabetes research.

Laboratory Investigation (2017) 97, 70-83; doi:10.1038/labinvest.2016.123; published online 28 November 2016

Islets of Langerhans and $\beta$-cell isolation constitute routinely used cell models for diabetic research. ${ }^{1}$ Many islet isolation protocols have been published, with the cell sources ranging from small rodents to humans; ${ }^{2-7}$ however, very few give all of the necessary and details to perform the intricate procedure. Many of the protocols are complex (such as those that require microsurgery) and time-consuming, and rarely correlate the phenotypic characteristics with extensive functional assessment. Furthermore, conflicting data are reported when it comes to islet yield, with a tendency to overestimate the purity of the preparations. ${ }^{8,9}$ Therefore, developing a reliable method that combines both functional and phenotypic characteristics is of great interest.

One of the main differences between the procedures described for the isolation of islets of Langerhans is the delivery route of the enzyme solution. The common bile duct (CBD) has been extensively used to deliver the enzyme, ${ }^{10-13}$ but the protocol is cumbersome and requires animal microsurgery expertise. Islet separation and purification from exocrine tissue is then performed by Percoll ${ }^{14,15}$ or Ficoll gradient, ${ }^{16}$ filtration, ${ }^{17}$ or magnetic retraction. ${ }^{18,19}$ To further increase the islet preparation purity, selection is manually performed under a microscope, yielding only a few hundred islets from a single rodent. ${ }^{10,13,16,20-24}$

Even more crucial than the isolation procedure is quantitative evaluation of islet quality and function assessment. Glucose-stimulated insulin secretion (GSIS) is a welldocumented and accepted measure of islet function. ${ }^{25-27}$ Pancreatic $\beta$-cells are extremely sensitive to extracellular glucose concentrations, and respond through a biphasic insulin secretion. The first phase consists of a rapid spike of insulin secretion (first phase), followed by a second-phase plateau that remains as long as the glucose stimulus lasts. ${ }^{28}$ These two insulin secretion phases are controlled by intracellular cytosolic calcium $\left(\mathrm{Ca}^{2+}\right)$, glucose-induced ATPsensitive $\mathrm{K}^{+}$channel inhibition, and voltage-gated $\mathrm{Ca}^{2+}$ channel activation result in the rapid elevation of cytosolic $\mathrm{Ca}^{2+}$ (first phase), followed by $\mathrm{Ca}^{2+}$ oscillation. ${ }^{29,30}$ The latter is mediated by other non-selective channels but remains highly complex and poorly understood. ${ }^{29-32}$ The intracellular

\footnotetext{
'Laboratoire de Recherche en Physiologie et Physiopathologie LRPP, Pôle Technologie Santé, Faculté de Médecine, Université Saint Joseph, Beirut, Lebanon and ${ }^{2}$ Laboratoire Rodolphe Mérieux, Pôle Technologie Santé, Faculté de Pharmacie, Université Saint Joseph, Beirut, Lebanon

Correspondence: Professor N Farès, Phd, Laboratoire de Recherche en Physiologie et Physiopathologie LRPP, Pôle Technologie Santé, Faculté de Médecine, Université Saint Joseph, Beirut 17-5208, Lebanon.

E-mail: nassim.fares@usj.edu.lb
}

Received 20 September 2016; accepted 21 October 2016 
$\mathrm{Ca}^{2+}$ stores have also been reported to have an important role in this insulin secretion, as well as other ATP-sensitive $\mathrm{K}^{+}$ channel-independent pathways. ${ }^{28,33,34}$ Therefore, glucosestimulated $\mathrm{Ca}^{2+}$ (GSCa) is also a reliable parameter for assessing islet function and viability. ${ }^{25,35}$ Furthermore, few studies contain glucose uptake monitoring with specific fluorescent probes, which could be valuable in demonstrating islet function. ${ }^{36-40}$

In the present study, we describe in detail a reproducible approach to isolate and assess the function of rodent islets, which may be useful for deciphering new cellular and molecular pathways in normal and diseased islet $\beta$-cells. Additionally, this approach was used to identify ion channel candidates implicated in rodent islet insulin secretion.

\section{MATERIALS AND METHODS}

\section{Animals}

The present study was approved by the ethical committee of the Saint Joseph University. The protocols were designed according to the Guiding Principles in the Care and Use of Animals approved by the Council of the American Physiological Society and were in adherence to the Guide for the Care and Use of Laboratory Animals published by the US National Institutes of Health (NIH Publication no. 85-23, revised 1996) and according to the European Parliament Directive 2010/63 EU. Male adult and aged C57BL/6 mice (3 and 10 months old), as well as male adult BALB/C mice (3 months old) and Wistar rats (3 months old), were used in this study and were obtained from Janvier Labs (Le Genest-Saint Isle, France). The animals were kept at a stable temperature $\left(25^{\circ} \mathrm{C}\right)$ and humidity $(50 \pm 5 \%)$ and were exposed to a 12:12-h light-dark cycle. They were fed ordinary rodent chow, had free access to tap water, and were acclimatized for at least 1 week under these conditions before the start of the study.

\section{Islet Isolation and Culture}

Animals were anesthetized by a mixture of ketamine $(75 \mathrm{mg} / \mathrm{kg}$; Interchemie, Waalre, Holland) and xylazine $(10 \mathrm{mg} / \mathrm{kg}$; RotexMedica, Trittau, Germany). Pedal withdrawal reflex was performed to make sure of adequate depth of anesthesia; when animals were completely non-responsive to toe pinching, an abdominal incision was performed aseptically and pancreases were harvested while avoiding the collection of fat tissue. Pancreases were then rinsed with cold modified Tyrode free-calcium solution with the following composition (in $\mathrm{mM}$ ): $140 \mathrm{NaCl}, 5.7 \mathrm{KCl}, 1.7 \mathrm{MgCl}_{2}, 4.4 \mathrm{NaHCO}_{3}, 1.5$ $\mathrm{KH}_{2} \mathrm{PO}_{4}, 10$ HEPES, 10 creatine monohydrate, 20 taurine, and 11.7 D-glucose, $\mathrm{pH} 7.2$, with $\mathrm{NaOH}$. They were gently cut into small pieces $(2 \mathrm{~mm})$ in modified Tyrode and washed several times with this solution to get rid of blood and possible fat tissue contamination. Thereafter, tissues were digested by one oxygenated enzymatic bath (100 r.p.m. shaker at $37^{\circ} \mathrm{C}$ ) for $60 \mathrm{~min}$. The bath contained $1 \mathrm{mg} / \mathrm{ml}$ collagenase A (Roche Diagnostics, Mannheim, Germany) that possesses a low-collagenase activity ( $>0.15 \mathrm{U} / \mathrm{mg}$ ) with $1 \mathrm{mg} / \mathrm{ml}$ bovine serum albumin (Sigma-Aldrich, St Louis, MO, USA). Digestion was stopped by the addition of an equal volume of ice-cold modified Tyrode and the tissue solution was vigorously hand shaken to dissociate mechanically the digested islets. The solution was then left on ice for $3 \mathrm{~min}$ to sediment the islets, and this step was repeated three times. To further purify the islets from contaminating exocrine tissue, a Percoll solution (Sigma-Aldrich) with a density of $1.045 \mathrm{~g} / \mathrm{ml}$ was used. First, a stock isotonic Percoll (SIP) solution was prepared by adding 9 parts of Percoll to 1 part of $1.5 \mathrm{mM} \mathrm{NaCl}(10 \times$ concentrated $)$, then this solution was diluted to $1.045 \mathrm{~g} / \mathrm{ml}$ by adding $0.15 \mathrm{mM} \mathrm{NaCl}$ using the following formula: $V_{\mathrm{y}}=V_{\mathrm{i}} \times\left(\rho_{\mathrm{i}}-\rho\right) /\left(\rho-\rho_{\mathrm{y}}\right)$, where $V_{\mathrm{y}}$ is the volume of diluting $0.15 \mathrm{mM} \mathrm{NaCl}, V_{\mathrm{i}}$ is the volume of SIP, $\rho_{\mathrm{i}}$ is the density of SIP, $\rho_{\mathrm{y}}$ is the density of $0.15 \mathrm{mM} \mathrm{NaCl}$, and $\rho$ is the density of final diluted Percoll solution. The digested pancreatic tissue was carefully placed on top of the $1.045 \mathrm{~g} / \mathrm{ml}$ Percoll solution and allowed to sediment for $5 \mathrm{~min}$. Islets were collected from the bottom of the tube and this step repeated three times. Finally, islets were cultured in RPMI-1640 (Lonza, Basel, Switzerland) supplemented with $2 \mathrm{mM}$ L-glutamine, $10 \%$ fetal bovine serum (FBS), and $1 \%$ penicillin/streptomycin, and the culture medium was changed on a daily basis. This isolation protocol was followed for all the rodent species used in this study, C57BL/6 (young and aged, male and female), BALB/C, and Wistar.

As described previously, ${ }^{10}$ to compare between the two methods, the CBD was also used to deliver the enzyme mixture in mice. Briefly, $1000 \mathrm{U} / \mathrm{ml}$ collagenase XI (SigmaAldrich) was injected into the pancreas. The pancreas was then excised and incubated at $37^{\circ} \mathrm{C}$ for $15 \mathrm{~min}$ in a solution with the same composition. After mechanical dissociation by hand shaking, the digestion was terminated by adding ice-cold modified Tyrode. After two brief centrifugations at $290 \mathrm{xg}$, the islets were collected on a $70 \mu \mathrm{m}$ filter and cultured in RPMI-1640 supplemented with $2 \mathrm{mM}$ L-glutamine, $10 \%$ FBS, and $1 \%$ penicillin/streptomycin.

\section{Dithizone Staining}

Islets were stained with the zinc-chelating dithizone (SigmaAldrich). Dithizone was first diluted with $95 \%$ ethanol, and then $\mathrm{NaOH}$ was added to a $\mathrm{pH}$ of 12 for complete dissolution of dithizone. The solution was further diluted with phosphate-buffered saline and the $\mathrm{pH}$ was adjusted to 7.2 with $\mathrm{HCl}$ before adding it onto the islets. Finally, cells were incubated with dithizone for $30 \mathrm{~min}$ at $37^{\circ} \mathrm{C}$.

\section{Islet Viability Tests}

Cell viability was assessed by Trypan blue exclusion test, propidium iodide, and MTT (3-(4,5-dimethylthiazol-2-yl)2,5-diphenyltetrazolium bromide). Following the pancreas digestion and for each consecutive day of culture, islets were labeled with Trypan blue (0.4\% in PBS) (Sigma-Aldrich). Trypan blue-positive and -negative islets were calculated with 
a hemocytometer. Trypan blue-negative islets were regarded as viable ones. The percentage of viable islets was calculated using the following formula: total viable cells (unstained)/ total cells (stained and unstained)x100. Islets were also stained with propidium iodide $(3 \mu \mathrm{M})$ and fluorescence was detected at $620 \mathrm{~nm}$. In addition, islets were stained with $0.5 \mathrm{mg} / \mathrm{ml}$ MTT water solution for $4 \mathrm{~h}$ at $37^{\circ} \mathrm{C}$ and then the MTT formazan purple crystals were dissolved with 100\% DMSO and absorbance was read at $550 \mathrm{~nm}$.

\section{$\mathrm{Ca}^{2+}$ Imaging}

Cultured islets grown for either 1 or 5 days were first washed two times with the modified Tyrode solution containing $1.5 \mathrm{mM}$ glucose and $1.5 \mathrm{mM} \mathrm{CaCl}_{2}$, and then incubated for $45 \mathrm{~min}$ at room temperature in modified Tyrode containing $3 \mu \mathrm{M}$ Fluo-4-AM (Thermo Fisher Scientific, Waltham, MA, USA) previously dissolved in DMSO. Islets were washed two times with modified Tyrode before starting the fluorescence recordings. To rule out the presence of an undetermined leak, leak control was performed by incubating the islets in modified Tyrode+ or $-\mathrm{Ca}^{2+}$ before starting the perfusion protocols. Then, GSCa was monitored by quickly shifting the solution to $16 \mathrm{mM}$ glucose. Triton X-100 (0.1\%) and ethylene glycol tetraacetic acid (EGTA, $10 \mathrm{mM}$ ) were consecutively added at the end of the perfusion protocols to check for the maximum and minimum fluorescence values. L-Arginine $(1 \mathrm{mM})$ and $\mathrm{KCl}(30 \mathrm{mM})$ were also used to assess potentiation of glucose-induced $\mathrm{Ca}^{2+}$ entry. The nonselective TRPC (transient receptor potential canonical) inhibitors 2-APB $(75 \mu \mathrm{M})$ and gadolinium $(100 \mu \mathrm{M})$ (Sigma-Aldrich) were added $10 \mathrm{~min}$ before the start of the recordings till the end of the perfusion experiments. 2-APB was dissolved in DMSO, while gadolinium was dissolved in ultrapure water. When $\mathrm{Ca}^{2+}$ imaging on transfected islets was performed, either transfected or non-transfected cells were analyzed after $48 \mathrm{~h}$ of transfection.

Fluorescence experiments were carried out at room temperature rather than at $37^{\circ} \mathrm{C}$ to reduce compartmentalization of Fluo-4-AM. ${ }^{41,42}$ Fluo-4 measurements were made using a Nikon Eclipse TS100-F inverted microscope and a Nikon HG lamp C-HGFI (Nikon Instruments, Melville, NY, USA). The $490 \mathrm{~nm}$ excitation light was focused onto cells by a 0.75 numerical aperture Plan Fluor objective with a magnification of x40 (Nikon Instruments). Emission was collected through the same objective, passed through a bandpass filter, and images were taken at $1 \mathrm{~Hz}$. For analysis, images were played back and the ratio $\left(\mathrm{F}_{1} / \mathrm{F}_{0}\right)$ of each image $\left(F_{1}\right)$ versus the first image $\left(F_{0}\right)$ of the series was recorded using the ImageJ and SigmaPlot v.11.0 softwares. These ratios were used to estimate intracellular $\mathrm{Ca}^{2+}$ concentrations $\left(\left[\mathrm{Ca}^{2+}\right] \mathrm{i}\right)$ as described by Grynkiewicz et al: ${ }^{43}\left[\mathrm{Ca}^{2+}\right] \mathrm{i}=K_{\mathrm{d}} \times$ $(\mathrm{Sf} 2 / \mathrm{Sb} 2) \times\left[\left(R-R_{\min }\right) /\left(R_{\max }-R\right)\right] . \mathrm{Sf} 2$ is the fluorescence measured at $516 \mathrm{~nm}$ in $\mathrm{Ca}^{2+}$-free solution, whereas $\mathrm{Sb} 2$ is the fluorescence measured at $516 \mathrm{~nm}$ in $\mathrm{Ca}^{2+}$ saturating conditions. The dissociation constant for $\mathrm{Ca}^{2+}$ binding, $K_{\mathrm{d}}$, was estimated to be $335 \mathrm{nmM}$ as stated by the manufacturer. As mentioned above, $R_{\max }$ was determined from islets dialyzed with $0.1 \%$ Triton X-100 in modified Tyrode containing $1.8 \mathrm{mM} \mathrm{CaCl}$, whereas $R_{\min }$ was determined from islets dialyzed with $0.1 \%$ Triton $\mathrm{X}-100$ in $\mathrm{Ca}^{2+}$-free modified Tyrode containing $10 \mathrm{mM}$ EGTA at the end of each experiment. Finally, $\mathrm{Ca}^{2+}$ entry amplitudes $\left(\Delta\left[\mathrm{Ca}^{2+}\right]_{\mathrm{i}}\right)$ were measured by subtracting the intracellular $\mathrm{Ca}^{2+}$ concentrations just before adding high glucose from those at the $\mathrm{Ca}^{2+}$ peak; $n=9-11$ islets from three mice. Data are represented as mean \pm s.e.m. in bar graphs.

\section{Glucose Uptake Monitoring}

Glucose uptake was assessed in the isolated islets using a fluorescent glucose, 2-[N-(7-nitrobenz-2-oxa-1,3-diazol-4-yl) amino]-2-deoxy-D-glucose (2-NBDG). Cultured islets were washed with glucose-free modified Tyrode and incubated for $25 \mathrm{~min}$ at $37^{\circ} \mathrm{C}$ in the same solution. Thereafter, 2-NBDG was added onto the cells to a final concentration of $200 \mu \mathrm{M}$ for $5 \mathrm{~min}$ at $37^{\circ} \mathrm{C}$. Cells were then washed with glucose-free modified Tyrode to eliminate background fluorescence and an image of the cells was acquired. The 2-NBDG incubation, washout, and imaging procedure were repeated five times for a total exposure of $25 \mathrm{~min}$ to 2-NBDG. Transmitted light images were also acquired after each incubation and washed out to verify that the islets were not disturbed by the solution changes. 2-NBDG was excited at $465-495 \mathrm{~nm}$ and emission collected at $515-555 \mathrm{~nm}$. Fluorescence intensity at each point was determined using ImageJ; after background subtraction, fluorescence intensity was calculated as the difference in the average fluorescence of cells before and after each application of 2-NBDG. To evaluate the effect of D-glucose on 2-NBDG uptake, all the incubations and washouts were performed as described previously, but with the presence of modified Tyrode containing $11.1 \mathrm{mM}$ glucose; $n=12-15$ islets from three mice. Data are represented as mean \pm s.e.m. in bar graphs.

\section{Insulin Secretion}

Static insulin secretion assays were performed on the islets, on the first day of isolation as well as on the fifth day of culture. As RPMI contains $11.1 \mathrm{mM}$ glucose, this medium was changed and islets were washed two times with the previously used modified Tyrode solution containing $1.5 \mathrm{mM}$ glucose and $1.5 \mathrm{mM} \mathrm{CaCl}_{2}$. Islets were then incubated with the modified Tyrode for $45 \mathrm{~min}$ at $37^{\circ} \mathrm{C}$ to establish basal insulin secretion; thereafter, the supernatant was removed and modified Tyrode, with either 1.5 or $16 \mathrm{mM}$ glucose, was readded for another $30 \mathrm{~min}$ at $37^{\circ} \mathrm{C}$. L-Arginine $(1 \mathrm{mM})$ and $\mathrm{KCl}(30 \mathrm{mM})$ were also used to assess the potentiation of glucose-induced insulin secretion.

Perifusion experiments were also performed to measure the kinetics of insulin release in response to glucose. Groups of 10 islets were perifused at $37^{\circ} \mathrm{C}$ with modified Tyrode containing $1.5 \mathrm{mM}$ glucose and $1.5 \mathrm{mM} \mathrm{CaCl} 2$ at a flow rate of 
$500 \mu \mathrm{l} / \mathrm{min}$ for $30 \mathrm{~min}$ to establish stable basal insulin secretion. Then, the glucose concentration was raised to $16 \mathrm{mM}$ and fractions were collected every $2 \mathrm{~min}$. When TRPC inhibitors were used, they were added $10 \mathrm{~min}$ before the highglucose stimulation. Insulin measurements on transfected islets were carried out $48 \mathrm{~h}$ after transfection. Finally, supernatants were collected and insulin was measured with the Insulin Mouse ELISA Kit according to the manufacturer's protocol (Abcam, Cambridge, UK).

\section{Islet Transfection}

Islets were transfected with siRNAs for $48 \mathrm{~h}$ before assessing TRPC1, 3, 4, and 6 knockout effects. The Turbofect Transfection Reagent (Thermo Fisher Scientific) was used according to the manufacturer's protocol. siRNA sequences were, from Eurogentec (Seraing, Belgium), as follows: siTRPC1 sense, 5'-CUGCUCAUCGUAACAACUA- ${ }^{\prime}$ and antisense, 5'-UAGUUGUUACGAUGAGCAG-3'; siTRPC 3 sense, 5'-CA UUCUCAAUCAGCCAACACGAUAU- $3^{\prime}$ and antisense, $5^{\prime}$-AUAUCGUGUUGGCUGAUUGAGAAUG- ${ }^{\prime}$; siTRPC4 sense, $5^{\prime}$-GGCUCAGUUCUAUUACAAA- $3^{\prime}$ and antisense, 5'-UUUGUAAUAGAACUGAGCC-3'; siTRPC6 sense, 5'-GG ACCAGCAUACAUGUUUA- $3^{\prime}$ and antisense, $5^{\prime}$-UAAACAU GUAUGCUGGUCC-3'; siScrambled sense, 5'-AAUACUCGC CCUAAUCCACAGAUAU-3' and antisense, 5'-AUAUCUG UGGAUUAGGGCGAGUAUU-3'.

\section{Gene Quantification}

Total RNA was extracted from the previously isolated and cultured islets using Trizol (Thermo Fisher Scientific) and chloroform. RNA was precipitated with isopropanol and then purified with ethanol $75 \%$ and the purity and concentration was determined by measuring the absorbance at $260 \mathrm{~nm}$ with the NanoDrop Spectrophotometer 2000 (Thermo Fisher Scientific, Wilmington, DE, USA). cDNA was synthesized using random primers $(250 \mathrm{ng} / \mu \mathrm{l})$, dNTP $(10 \mathrm{mM})$, and the Superscript II Reverse Transcriptase Kit (Thermo Fisher Scientific). Quantitative real-time PCR was conducted using the 7500 Real-time PCR System and the SYBR Green PCR Master Mix (Thermo Fisher Scientific). Samples were run in triplicates. Dissociation curves were performed at the end of the amplification to confirm the specificity of the amplified PCR products. In addition, 'no RT' control reactions were carried out by omitting the reverse transcriptase to confirm the absence of contaminating genomic DNA. Glyceraldehyde 3-phosphate dehydrogenase (GAPDH) was used as a housekeeping gene, and quantifications were conducted using the $2^{\Delta \Delta \mathrm{Ct}}$ method. The primers (Eurogentec, Seraing, Belgium) used were as follows: bax F, 5'-GGCTGGACACTGGAC TTCCT-3' and R, 5'-GGTGAGGACTCCAGCCACAA-3'; casp2 $\mathrm{F}, 5^{\prime}$-GGCTACAATGTCCATGTGCT- $3^{\prime}$ and R, 5' - CC ACTACGCAGGAGTCTGTG-3'; casp6 F， 5'-TCAGGGCT AGGACACCG-3' and R, 5' ${ }^{\prime}$-TTGAAGATGAGGGCAACTC C-3'; bcl2 F, 5'-TTCGCAGAGATGTCCAGTCA-3' and R, 5'-TTCAGAGACAGCCAGGAGAA-3'; bag1 F, 5'-GAAACA
CCGTTGTCAGCACT- $3^{\prime}$ and R, 5'-GCTCCACTGTG TCACACTC-3'; casp3 F, 5'-CAAGTCAGTGGACTCTGG GA-3' and R, 5'-CGAGATGACATTCCAGTGCT-3'; ins1 F, 5'-GAAGCGTGGCATTGTGGAT-3' and R, 5'-TGGGCCTT AGTTGCAGTAGTTCT-3'; ins2 F, 5'-AGCCCTAAGTGAT CCGCTACAA-3' and R, 5'-CATGTTGAAACAATAACCTGG AAGA-3'; $\operatorname{trpc1}$ F, 5'-AGCCTCTTGACAAACGAGGA-3' and $\mathrm{R}, 5^{\prime}$-ACCTGACATCTGTCCGAACC-3'; $\operatorname{trpc3} \mathrm{F}, 5^{\prime}$-GAGA TCTGGAATCGGTGGAA-3' and R, 5'-AAAAGCTGCTGT TGGCAGTT-3'; $\operatorname{trpc4} \mathrm{F}$, 5'-GACACGGAGTTCCAGAGAG C-3' and R, 5'-GTTGGGCTGAGCAACAAACT-3'; $\operatorname{trpc6} \mathrm{F}$, 5'-TACTGGTGTGCTCCTTGCAG-3' and R, 5'-GAGCTTG GTGCCTTCAAATC-3'; gapdh F, 5'-GGAGAGTGTTTCCTC GTCCC-3' and R, 5' ${ }^{\prime}$-ATGAAGGGGTCGTTGATGGC-3'.

\section{Statistical Analysis}

All quantitative data are reported as means \pm s.e.m. Statistical analysis was performed with the SigmaPlot software (v.11.0). When two conditions were compared, Student's $t$-tests or Mann-Whitney U-tests were used depending, respectively, on the presence or absence of a normal distribution. KruskalWallis one-way analysis of variance on ranks tests were performed for multiple comparisons of the values because the normal distribution verified with the Shapiro-Wilk test was not met. All values with $P<0.05$ were considered significant.

\section{RESULTS}

\section{Islet Yield and Purity}

After digestion of the pancreas and Percoll separation, most of the mouse islets were collected from the bottom of the tube, with some remaining cells in the upper phase mixed along with pancreatic acini. To collect relatively pure islets, cell solution was allowed to sediment for only $5 \mathrm{~min}$ on top of the Percoll solution. Islets were spheroid with a brownish color and refringent edges and were red stained with dithizone (Figures 1a and b). The method was reproducible and yielded a relatively constant number of islets (Figure 1c) that was equal to $990 \pm 112$ per pancreas (Figure 1d). Islet size frequency was distributed between $<100$ and $>350 \mu \mathrm{m}$, with the highest frequency between 100 and $200 \mu \mathrm{m}$ (Figure 1e). Over $80 \%$ of the cell preparation consisted of islets on the day of isolation, and this percentage increased gradually till $100 \%$ of the fourth day of culture; the rest of the cells were pancreatic acini that got eliminated quickly from the cell culture medium (Figure 1f).

\section{Islet Viability and Sustenance}

First, viability was assessed using propidium iodide (Figures 2a-c), Trypan blue (Figures $2 \mathrm{~d}$ and e), and MTT (Figure 2f). Few mouse islets stained positive with the first two solutions $(\sim 6 \%)$ on the day of isolation and this percentage remained relatively stable until the fifth day of culture, indicating the obtainment of healthy islets and optimal culture conditions. Additionally, an MTT colorimetric assay showed a stable cell metabolism. 

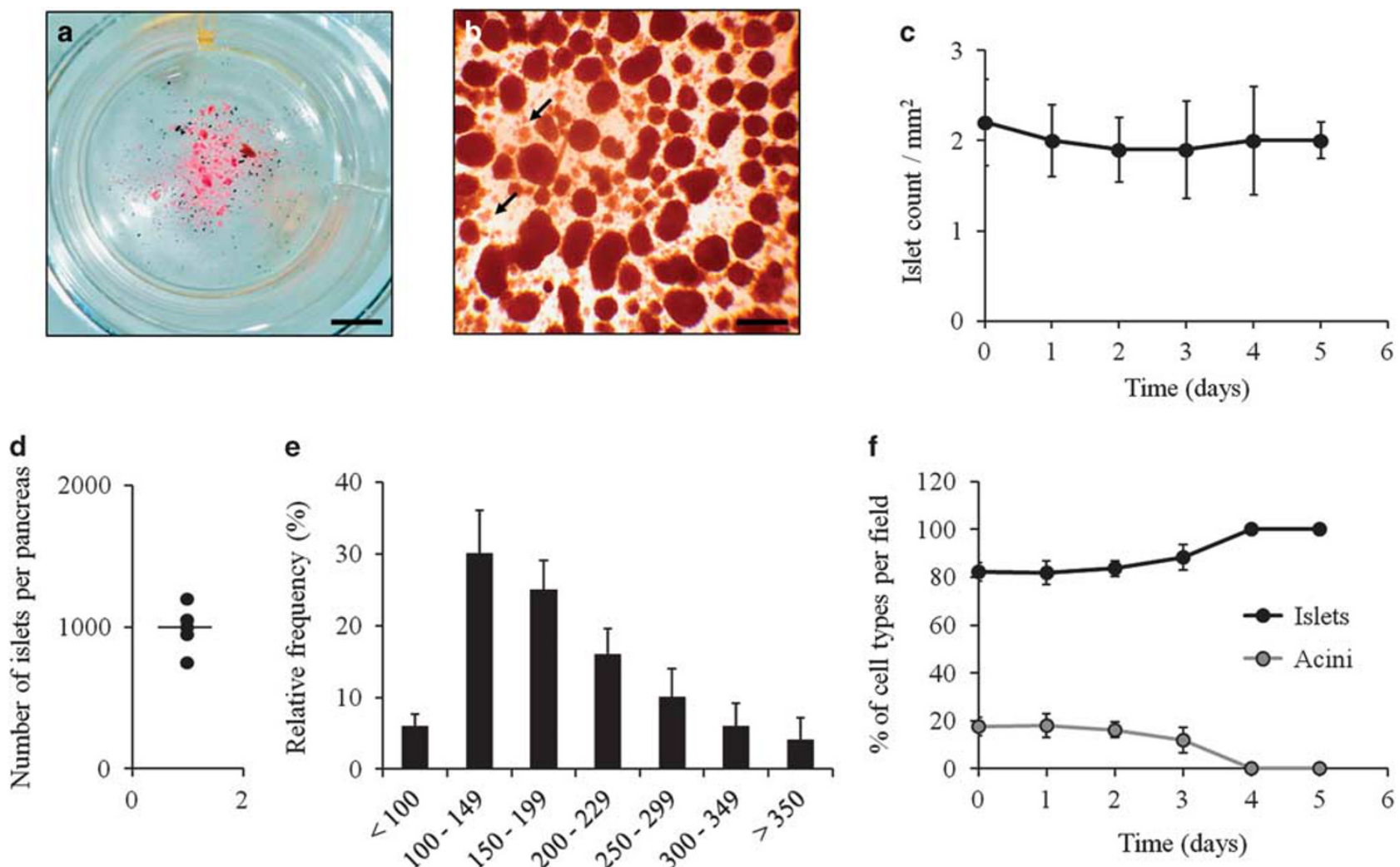

Mean diameter $(\mu \mathrm{m})$

Figure 1 Significant islet yield after pancreatic digestion. (a and $\mathbf{b}$ ) Representative photograph and light microscopy image of freshly isolated mouse pancreatic islets stained with dithizone. (c) Islet numbers per square millimeter of culture well from the day of pancreatic isolation till day 5 of culture. (d) Islet yield per pancreas obtained from different cell preparations. (e) Relative frequency distribution of the size of islets isolated from adult male mice. (f) Percentage of cell types (islets and exocrine acini) obtained along the 5-day culture. Arrows in (b) show pancreatic exocrine acini that are not stained with dithizone. Magnification: $x 4$ in (a) and $\times 100$ in (b). Scale bars: $1.4 \mathrm{~mm}$ in (a) and $150 \mu \mathrm{m}$ in (b); $n=5$ mice. Data are represented as mean \pm s.e.m.

Furthermore, islet status was verified by studying the expression of pro- and antiapoptotic genes, bax, casp2, casp3, casp6, bag1 and bcl2, that remained stable throughout the duration of the culture (Figures $3 \mathrm{a}$ and $\mathrm{b}$ ). Islet-specific proinsulin genes, ins 1 and ins2, were also stable during the 5-day culture (Figure 3c).

\section{Islet Yield Within Age, Sex, and Different Rodent Species} The reproducibility of the islet isolation protocol among different rodent species as well as the effect of sex and age on cell yield was evaluated. Ten-month-old male and female C57BL/6 mice were used with no significant differences in the number of obtained islets (Figure $4 \mathrm{a}$ ); in addition, similar numbers were obtained from male BALB/C pancreases (Figure $4 \mathrm{~b}$ ). Pancreases from male Wistar rats were digested using the same protocol and higher islet numbers were obtained (Figure 4b). Dithizone staining revealed that rat islets count remained stable during the 5-day culture (Figures $4 \mathrm{c}-\mathrm{e}$ ), and also the cells viability, which was revealed by propidium iodide staining (Figure $4 \mathrm{f}$ ).

\section{Islet Function Assessment}

After $24 \mathrm{~h}$ of culture in RPMI, the overall health of the islets was assessed by GSCa and GSIS. Islets were loaded with Fluo- 4 in the presence of $1.5 \mathrm{mM}$ glucose and then stimulated with $16 \mathrm{mmol} / \mathrm{l}$ glucose. This glucose concentration was chosen instead of $11 \mathrm{mM}$, as the most apparent difference between the $\mathrm{Ca}^{2+}$ oscillations in 11 and $16.7 \mathrm{mM}$ glucose was its longer duration at the latter concentration, with little or no change in amplitude. ${ }^{44}$ Upon changing the medium, the Fluo-4 signal decreases briefly before giving the first phase a swift rise, which is followed by the second slower but longer lasting oscillation (Figures 5a-c). The initial duck in fluorescence signal could be caused by changes in intracellular $\mathrm{Ca}^{2+}$ levels because of $\mathrm{Ca}^{2+}$ uptake by the endoplasmic reticulum. After 5 days of culture, islets responded with a similar GSCa, indicating the intact function of the cells (Figure 5a). Intracellular $\mathrm{Ca}^{2+}$ amplitudes were comparable for the first and second phase between the first and the fifth day of culture (Figure $5 b$ ). The addition of Triton X-100, which permeabilizes the cells, elicited a higher $\mathrm{Ca}^{2+}$ entry, whereas the 

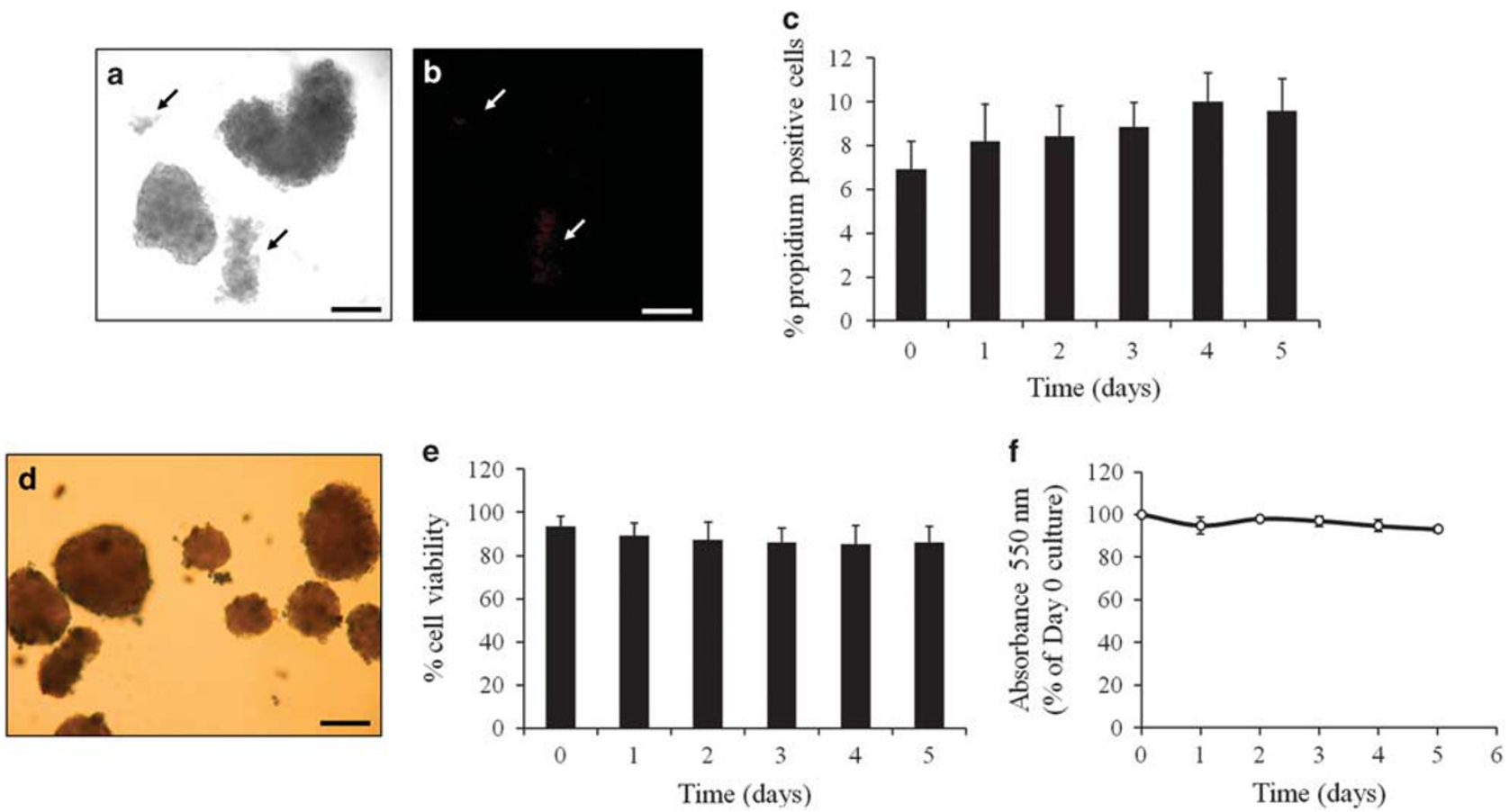

Figure 2 Viability of mouse isolated and cultured islets. Representative light (a) and fluorescence (b) microscopy assessing cell viability with the use of propidium iodide. (c) Percentage of propidium iodide-positive islets throughout the 5-day culture period. (d and e) Representative light microscopy and histograms showing Trypan blue exclusion viability test for the 5-day culture period. (f) MTT colorimetric assay for the indicated days of islet culture. Arrows in (a and $\mathbf{b}$ ) show dead pancreatic exocrine acini. Magnification: x400. Scale bars: $40 \mu \mathrm{m} ; n=5$ mice. Data are represented as mean \pm s.e.m.
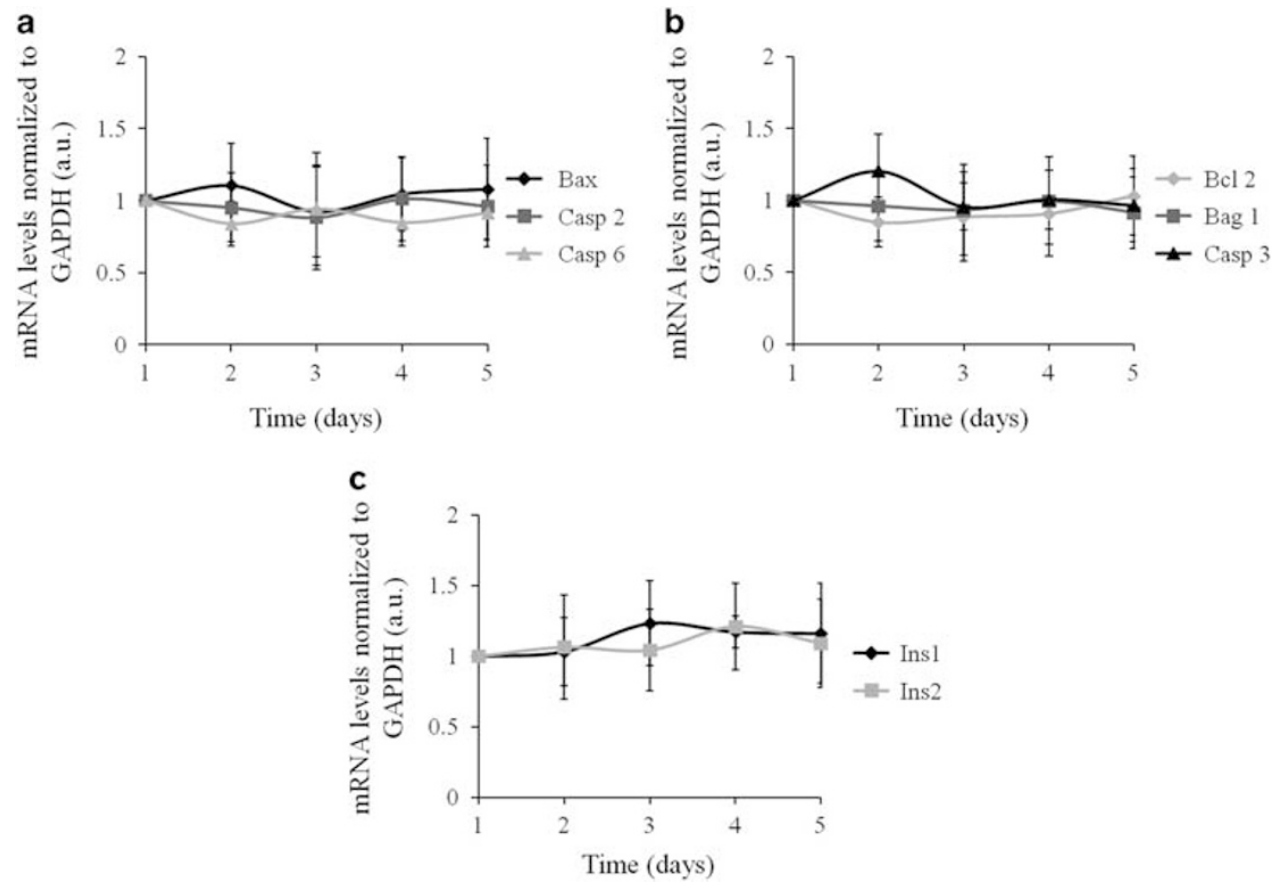

Figure 3 Islet maintenance in culture. (a-c) Relative mRNA levels of pro- and antiapoptotic as well as islet-specific genes in the cultured mouse islets. Relative glyceraldehyde 3-phosphate dehydrogenase (GAPDH) was used as a housekeeping gene (a.u., arbitrary units); $n=5$ mice. Data are represented as mean \pm s.e.m. 

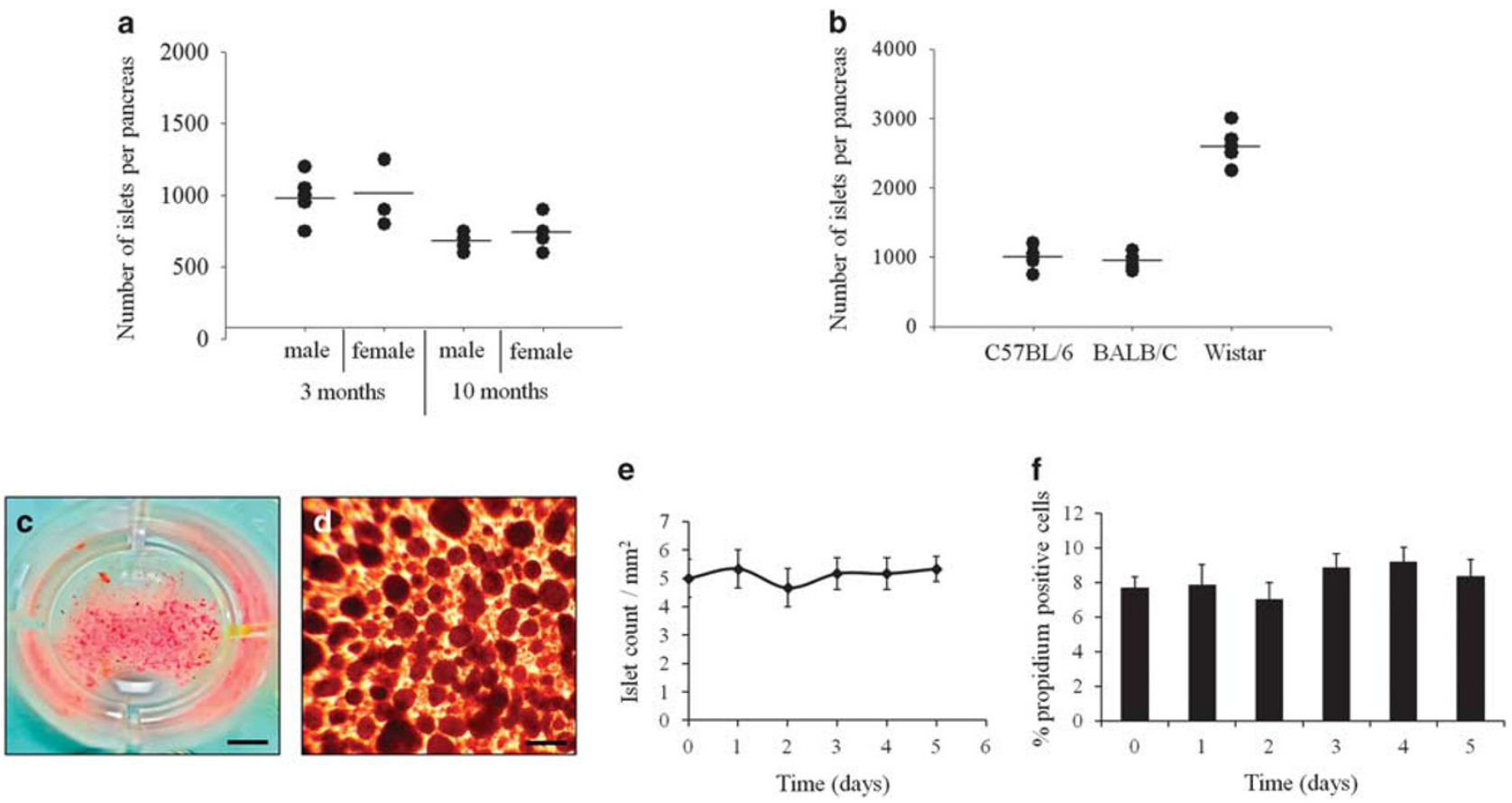

Figure 4 Effect of age, sex, and rodent species on islet yield. (a) Number of islets obtained from 3-and 10-month-old male and female mice. (b) Number of islets isolated from male BALB/C mice as well as Wistar rats. (c and d) Representative photograph and light microscopy image of freshly isolated rat pancreatic islets stained with dithizone. (e) Rat islet numbers per square millimeter of culture well from the day of isolation till day 5 of culture. (f) Percentage of propidium iodide-positive rat islets throughout the 5-day culture period. Magnification: $\mathrm{x} 4$ in (c) and x100 in (d). Scale bars: $1.4 \mathrm{~mm}$ in (c) and $150 \mu \mathrm{m}$ in (d); $n=5$ animals for each experiment. Data are represented as scatter plots and mean \pm s.e.m.

$\mathrm{Ca}^{2+}$-chelating EGTA diminished this response. Similarly, $\mathrm{L}$-arginine and $\mathrm{KCl}$, which depolarize the cells, increased the intracellular $\mathrm{Ca}^{2+}$ levels, and these effects were comparable between the first and the fifth day of culture (Figure 5b). GSIS was also evaluated; basal insulin secretion was measured in islets cultured in $1.5 \mathrm{mM}$ glucose, while GSIS was measured after stimulation with $16 \mathrm{mM}$ glucose in the presence or absence of L-arginine and $\mathrm{KCl}$. Similar insulin secretion kinetics were obtained on the first and fifth day of culture, indicating a healthy islet status and favorable culture conditions (Figures $5 \mathrm{~d}$ and e).

Studying glucose uptake in islets may provide new insights into the mechanisms of glucose transport and their alteration in disease states such as diabetes. Therefore, a fluorescent glucose analog 2-NBDG was used to evaluate the function of the islet. After starving the islets, 2-NBDG was added and fluorescence quantified over time. Fluorescence intensity increased exponentially the first $10 \mathrm{~min}$ to attain an eventual plateau starting at minute 15 (Figure 6a). Before 2-NBDG exposure, islets presented faint background fluorescence and were then clearly discerned after $5 \mathrm{~min}$ of incubation with 2 -NBDG (Figure 6b). To determine whether 2-NBDG is transported through the same pathway as D-glucose, the fluorescent analog was added along with D-glucose. Fluorescence intensity significantly decreased in the presence of $11.1 \mathrm{mM}$ D-glucose, demonstrating that D-glucose competes with 2-NBDG for glucose transporters (Figure 6c).

\section{Comparison with a Commonly Used Protocol}

The present approach was compared with the most commonly used islet isolation protocol that consists of injecting the enzymes via the CBD. The present protocol took more time to complete than the CBD approach, but with greater flexibility in enzyme digestion time (Figure 7a). Higher islet yield was obtained using the present approach (Figure $7 \mathrm{~b}$ ), but with an $\sim 5 \%$ lower islet purity on the first 3 days of culture (Figure 7c). Cell viability was similar for the two protocols as assessed by propidium iodide staining (Figure $7 \mathrm{~d}$ ). When the islet function assessment was performed, $\mathrm{Ca}^{2+}$ signaling was comparable in cells obtained from both protocols, and the two $\mathrm{Ca}^{2+}$ phases were intact during the 5-day culture (Figure 7e). Finally, insulin secretion as well as glucose uptake was comparable between the two approaches on the first as well as on the fifth day of culture (Figures $7 \mathrm{f}-\mathrm{h}$ ). The 2-NBDG fluorescence curve over time was similar in islets obtained from both protocols. In fact, fluorescence intensity increased exponentially the first $10 \mathrm{~min}$ to eventually attain a plateau (Figure 7g). Additionally, when 2-NBDG was added along with $11.1 \mathrm{mM}$ D-glucose, fluorescence intensity significantly decreased, demonstrating that D-glucose competes with 2-NBDG for glucose transporters. There was no significant difference between the fluorescence decrease in islets from both protocols, indicating that glucose transport is similar between the islets (Figure $7 \mathrm{~h}$ ). 
a

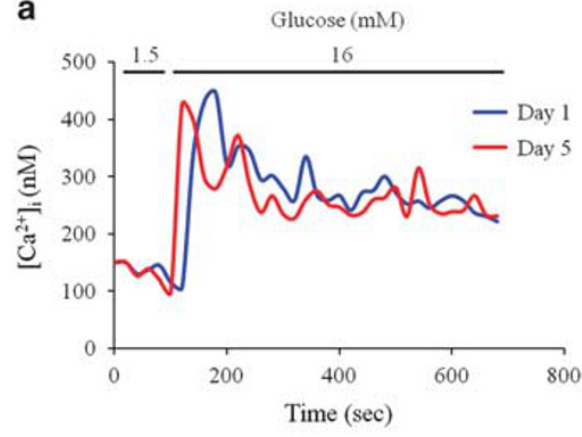

b

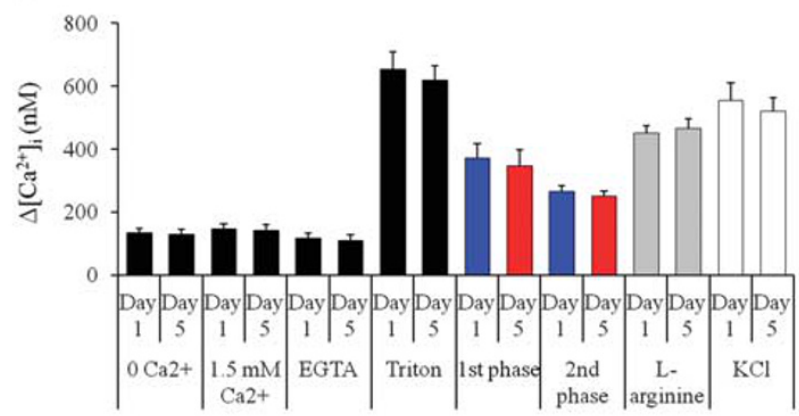

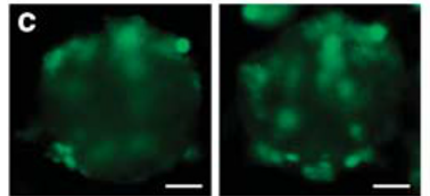

d

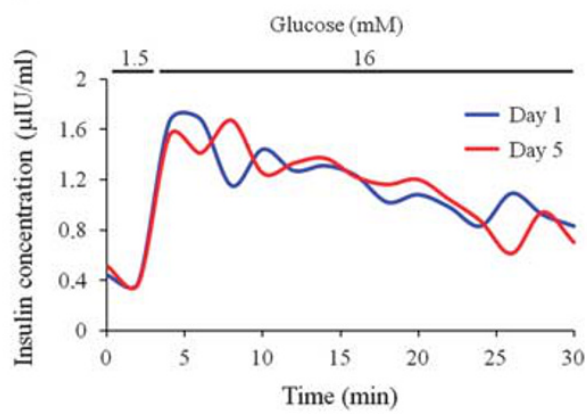

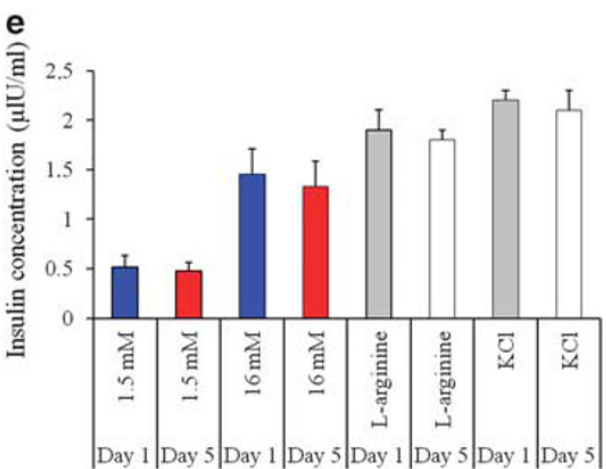

Figure 5 Glucose-stimulated $\mathrm{Ca}^{2+}$ and insulin secretion in isolated mouse islets. (a) Representative recordings of intracellular $\mathrm{Ca}^{2+}$ concentrations showing the effect of $16 \mathrm{mM}$ glucose addition on $\mathrm{Ca}^{2+}$ entry in isolated islets on day 1 and day 5 after pancreatic digestion. (b) Amplitudes of intracellular $\mathrm{Ca}^{2+}$ concentrations $\Delta\left[\mathrm{Ca}^{2+}\right]_{i}$ were measured by subtracting the concentration values just before adding high glucose from those at the $\mathrm{Ca}^{2+}$ peak, with or without the presence of $\mathrm{L}$-arginine and $\mathrm{KCl}$. Amplitudes of the first rapid phase $\mathrm{Ca}^{2+}$ peak as well as the second slower $\mathrm{Ca}^{2+}$ oscillation phase were measured on day 1 and day 5 of culture. (c) Representative images of Fluo-4-loaded isolated islets before (left) and after (right) stimulation with $16 \mathrm{mM}$ glucose. (d) Representative traces of insulin release during perifusion experiments of islets on days 1 and 5 of culture. (e) Static insulin secretion $(\mu \mathrm{lU} / \mathrm{ml})$ was measured using ELISA before and after glucose challenge $(16 \mathrm{mM})$ on day 1 and 5 of culture, with or without the presence of L-arginine and $\mathrm{KCl}$. Magnification: x600. Scale bars: $25 \mu \mathrm{m} ; n=9-11$ islets from three mice. Data are represented as mean \pm s.e.m.

\section{TRPC Channels are Implicated in $\mathrm{Ca}^{2+}$-Mediated Insulin Secretion}

To determine whether TRPC channels are implicated in insulin secretion, islets were perifused with low followed by high glucose concentrations, with or without TRPC inhibitors, 2-APB and gadolinium. TRPC1/3/4/6 knockdown were also performed to validate the role of these channels in insulin secretion. Real-time PCR demonstrated efficient knockdown of the respective TRPC channels (Figure 8a). Both 2-APB and gadolinium inhibited the first rise in calcium as well as in insulin secretion, whereas almost completely abrogated the second $\mathrm{Ca}^{2+}$ and insulin phases as compared with the control islets and the ones treated with the vehicle DMSO (Figures $8 \mathrm{~b}-\mathrm{e}$ ). Similar results were obtained with the TRPC1/3/4/6 knockdown as compared with the islets transfected with the siScrambled (Figures 8b-e).

\section{DISCUSSION}

Isolated islets are in demand for in vivo transplantation and for determining new pathophysiological signaling pathways. ${ }^{3,22,45-48}$ These needs caused us to revisit methods for obtaining highly pure islet preparations that retain their in vivo functions. Previously published protocols have described islet isolation from rodents, but these studies often lack essential detail and do not produce large numbers of pure and functional islets. The protocol described here is straightforward and can be easily followed as it does not require previous expertise in the field. Most of the literature makes use of $\mathrm{CBD}$ to deliver the enzyme solution, thus requiring surgical ability. $6,10,21,22,25$ In addition, most of the described enzyme solutions used possess high collagenase activity, such as collagenase P, IV, V, XI, and liberase blends, which makes digestion time an important limiting factor. ${ }^{10,21,49-54}$ Herein, the pancreas was directly excised and digested with a low-collagenase solution, thus eliminating the digestion time-limiting factor and the need for surgical expertise. Islets were then purified using a Percoll solution; Percoll has the advantage of being chemically inert with less toxic effects on the cells, eliminating the need of performing several washes and thus stressing the islets after the gradient step. Many protocols use Ficoll or histopaque; however, others have questioned the use of such compounds because of their cellular toxicity. ${ }^{17,55,56}$ The contrast agent iodixanol 

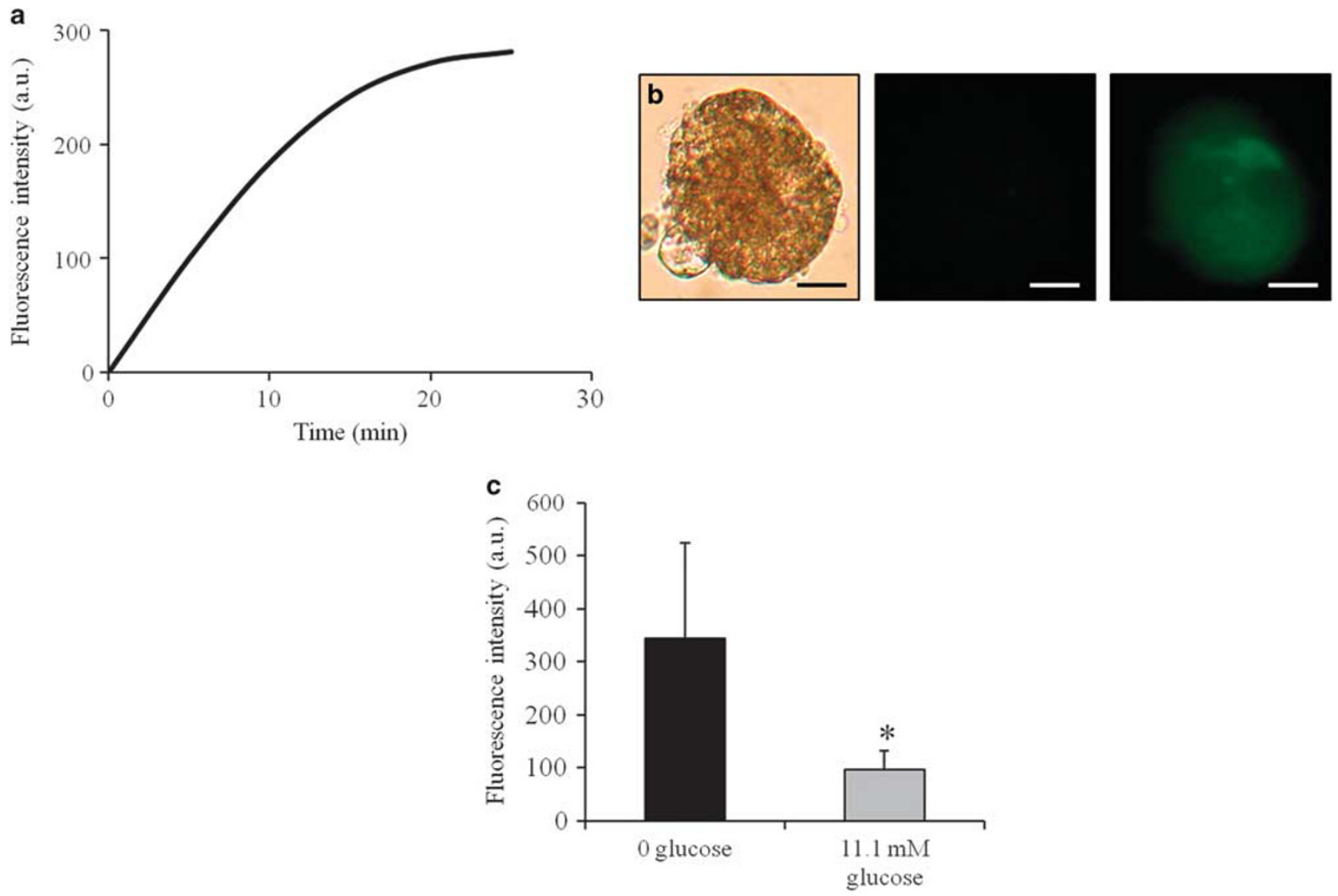

Figure 6 Kinetic analyses of 2-NBDG uptake in isolated mouse islets. (a) Representative time course of 2-NBDG uptake in isolated mouse islets after 5 days of culture. Islets were incubated with $0 \mathrm{mM}$ D-glucose modified Tyrode containing 2-NBDG. (b) Representative light (left) and fluorescence microscopy before (middle) and after (right) incubation of islets with 2-NBDG. (c) Effect of D-glucose (11.1 mM) addition on 2-NBDG uptake by cultured islets (a.u., arbitrary units). Magnification: $\times 600$. Scale bars: $25 \mu \mathrm{m} ; n=12-15$ islets from three mice. Data are represented as mean \pm s.e.m. ${ }^{*} P<0.05$ vs 0 glucose.

has been also used with interesting cellular yield and viability, ${ }^{55,57,58}$ but when financial considerations are taken into account, Percoll remains the best solution. This last purification step was repeated three times to eliminate most of the exocrine tissue; many protocols have recourse to manual selection, which can be time-consuming. ${ }^{10,11,25}$

RPMI-1640 medium has been shown to be optimal for maintaining islets into culture ${ }^{59}$ and was therefore used in the present study. Exocrine tissue cells secrete a variety of digestive enzymes, which have been shown to affect negatively islet health and decrease GSIS. ${ }^{60}$ Few remaining exocrine acini were obtained after the Percoll purification step; however, most of this tissue contained dead cells as revealed by Trypan blue and propidium iodide, and these remnants were completely eliminated after 3 days of culture. In addition, islet fragmentation has been noted and associated with an islet diameter of $<100 \mu \mathrm{m},{ }^{61}$ but in our study the highest frequency of size distribution was between 100 and $200 \mu \mathrm{m}$, indicating the absence of tissue fragmentation. Finally, it has been demonstrated that islets subjected to harsh conditions while digesting pancreas, and culturing thereafter can result in survival impairment and activation of several death pathways, mediating islet loss of integrity. ${ }^{62,63}$ In the present study, cell viability was stable throughout the duration of culture as assessed by Trypan blue, propidium iodide, and MTT, indicating favorable isolation and culture conditions. In fact, these simple cell viability and metabolism assays have been shown as reliable tools correlating with islet health and function. ${ }^{25,64}$ In addition, and as the expression profile of bcl and caspases proteins has been used as a molecular marker for islet cell death, we sought to evaluate the expression of these proteins as an early indicator for apoptosis and as a molecular marker for the general healthy status of the cells. In fact, the role of caspases in the regulation of apoptotic rodent as well as human pancreatic islet $\beta$-cells such as in glucotoxic conditions has been well determined. ${ }^{65,66}$ Several in vitro studies have suggested that caspase- 3 activation is essential for $\beta$-cell apoptosis. ${ }^{67,68}$ Other studies have indicated that chronic hyperglycemia increases cell death through the intrinsic apoptotic pathway by activating bax and caspase- $3 .{ }^{69}$ Moreover, bcl2 family and bax have been used as molecular markers for islet cell death by apoptosis. ${ }^{70}$ High glucose has 


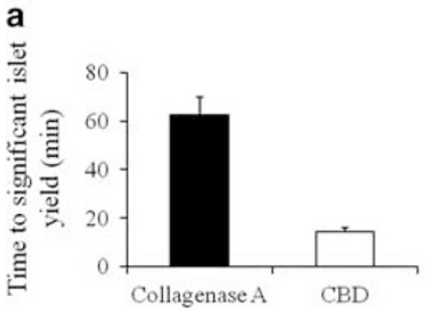

b

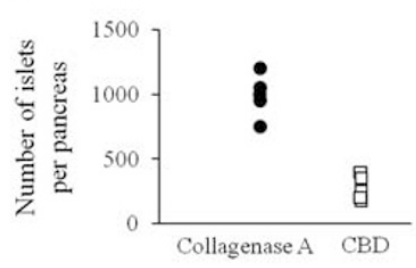

c

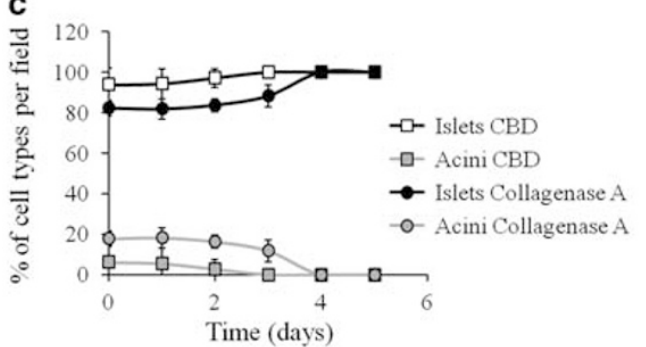

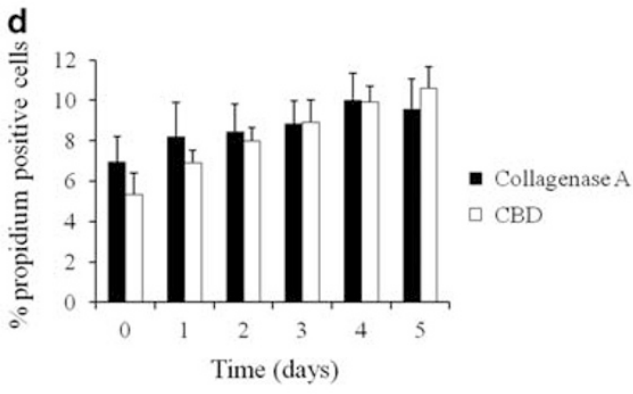
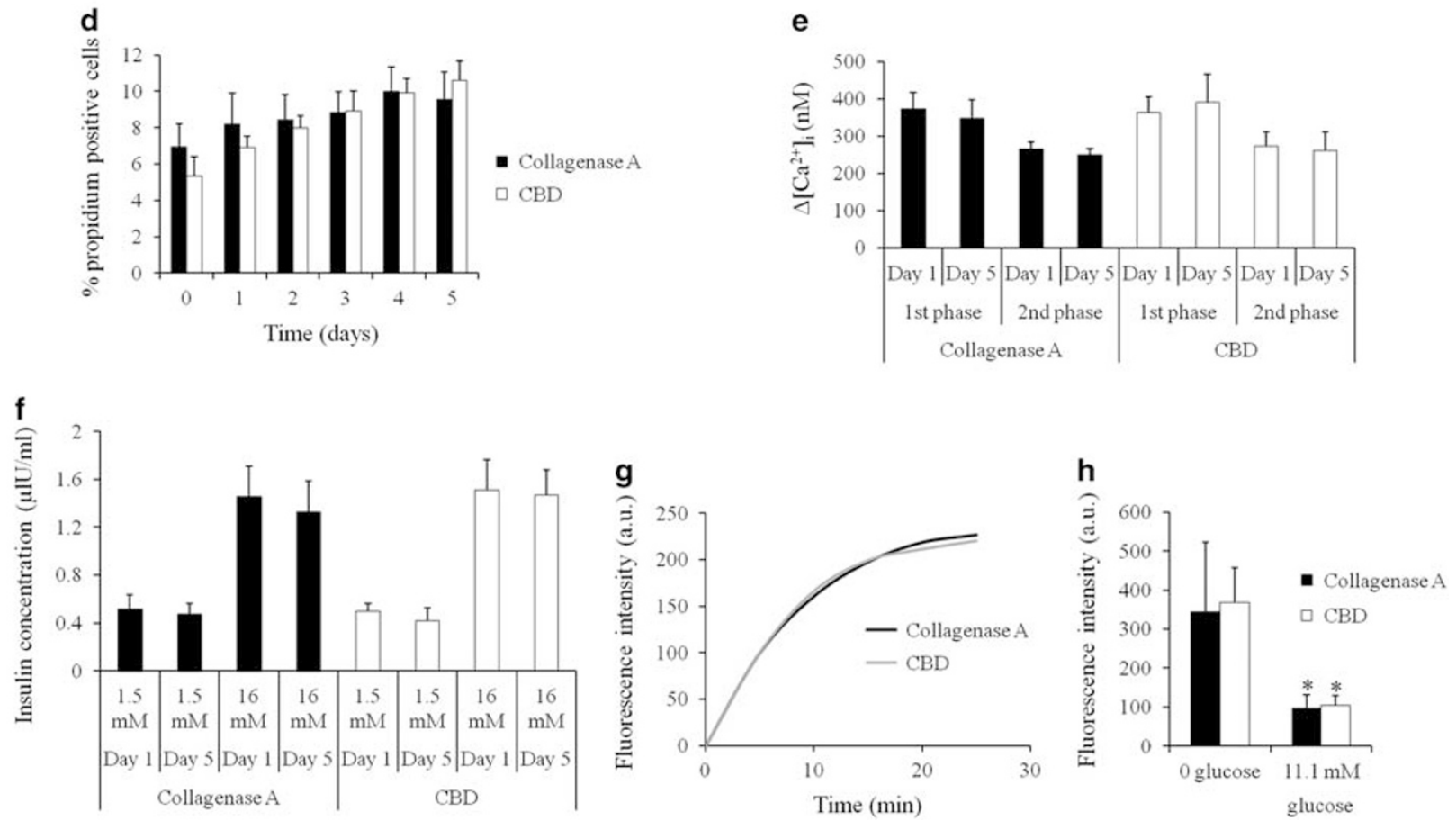

Figure 7 Protocol comparison with the common bile duct enzyme (CBD) injection method. (a) Necessary enzyme incubation time (min) for obtaining significant islet yield in the two protocols. (b and c) Islet yield and cell purity comparison between the two protocols. (d) Percentage of propidium iodide-positive islets throughout the 5 - day culture period, obtained from both type of preparations. (e) Amplitudes of intracellular $\mathrm{Ca}^{2+}$ concentrations $\Delta\left[\mathrm{Ca}^{2+}\right]_{\mathrm{i}}$ measured on days 1 and 5 of islet culture from both preparations. Amplitudes of the first rapid phase $\mathrm{Ca}^{2+}$ peak as well as the second slower $\mathrm{Ca}^{2+}$ oscillations phase were measured by subtracting the concentration values just before adding high glucose from those at the Ca ${ }^{2+}$ peak. (f) Static insulin secretion $(\mu \mathrm{lU} / \mathrm{ml})$ was measured before and after glucose challenge $(16 \mathrm{mM})$ on days 1 and 5 of islet culture from both preparations. (g) Representative time course of 2-NBDG uptake in isolated mouse islets from both protocols after 5 days of culture. (h) Effect of D-glucose (11.1 mM) addition on 2-NBDG uptake by cultured islets obtained from both protocols; $n=9-11$ islets from five mice for each condition. Data are represented as scatter plots and mean \pm s.e.m.

been shown to cause apoptosis of human pancreatic islet cells in vitro, possibly by unbalancing the expression of several bcl family members. ${ }^{71}$ Also, bcl2, bax, and caspase-3 have been shown as critical mediators in high-glucose-mediated islet apoptosis. ${ }^{72,73}$ Finally, bag-1 overexpression in islets seemed to enhance protection from apoptosis. ${ }^{74}$ In the present study, the expression of pro- and antiapoptotic, as well as isletspecific genes, was stable during the culture period, indicating an overall healthy islet cell status.

Variations in the total islet mass per pancreas as well as the cellular-type composition has been shown to exist between inbred mice strains, and the islet number seemed to depend greatly on the genetic background; ${ }^{75}$ in addition, age differences among the same animal species have been noted. ${ }^{76,77}$ Thus, extremely various islet yields have been described ranging from a few hundred to several thousand. Consequently, after taking into account the different methods of isolation and the enzyme solutions used, it is difficult to predict a precise yield for each animal strain. To evaluate the reproducibility of the present protocol among rodents, islets from male and female mice of different ages as well as from rats were isolated. Neither sex nor mouse strain affected the yield, but a tendency to a slightly lower islet count was noted with age. In fact, age has been shown to result in islet dysfunction and cell cultures that are more difficult to maintain. ${ }^{76,78-80}$ In addition, a higher yield was obtained 

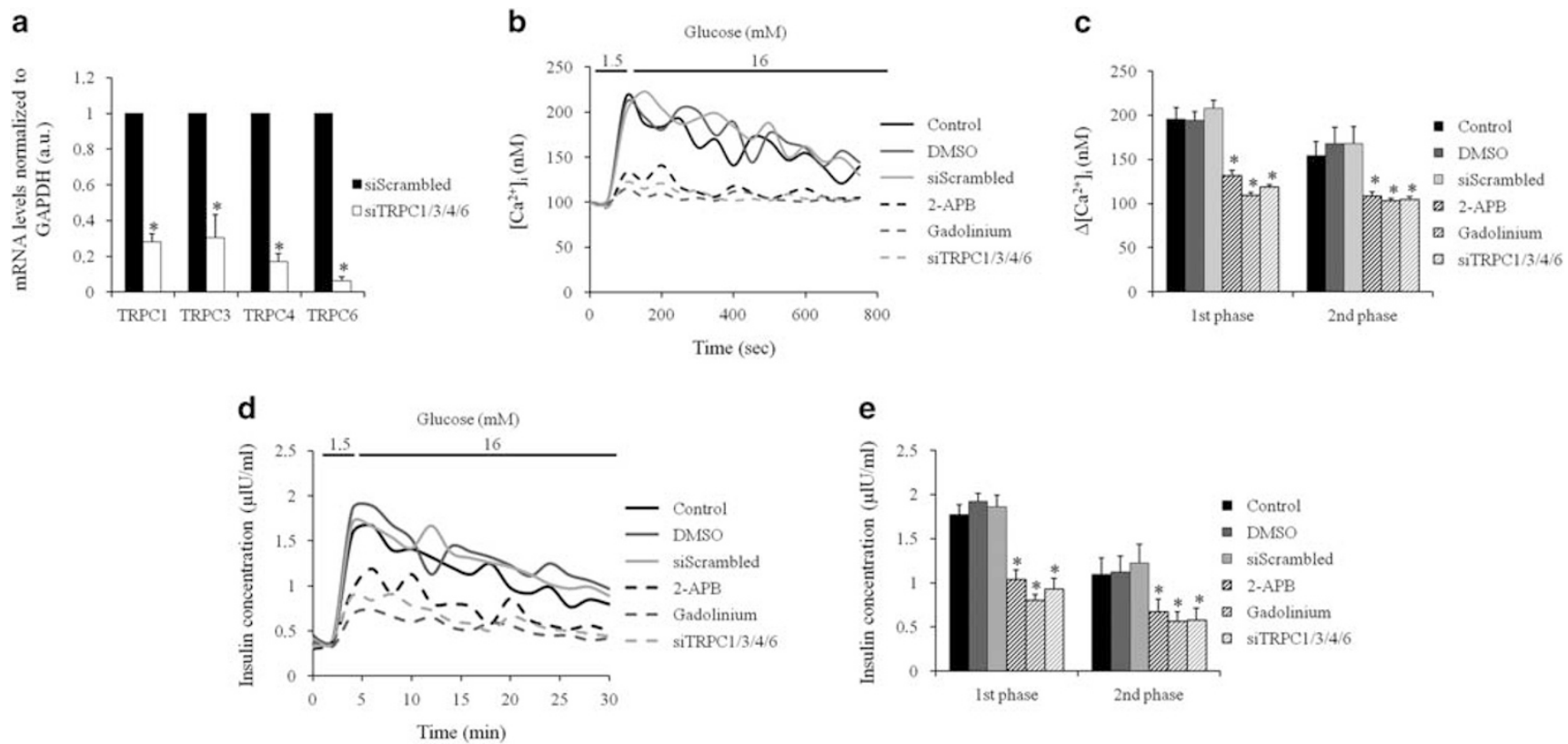

Figure 8 TRPC channels implication in insulin secretion. (a) Quantitative PCR showing the relative TRPC1, 3, 4, and 6 mRNA levels after knockdown of their respective genes. mRNA levels were normalized to glyceraldehyde 3-phosphate dehydrogenase (GAPDH) (a.u. arbitrary units). (b and c) Representative recordings as well as amplitudes of intracellular $\mathrm{Ca}^{2+}$ concentrations $\Delta\left[\mathrm{Ca}^{2+}\right]_{\mathrm{i}}$ showing the effects of different TRPC channel blockers and knockdown on GSCa. (d and e) Perifusion and static insulin secretion $(\mu \mathrm{lU} / \mathrm{ml})$ measured before and after glucose challenge $(16 \mathrm{mM})$ with or without the different TRPC channel blockers and knockdown; $n=9-11$ islets from four animals for each condition. Data are represented as scatter plots and mean \pm s.e.m. ${ }^{*} P<0.01$ vs Control, dimethyl sulfoxide and siScrambled.

with rats as compared with mice, which could be because of the weight of the mammal species as described previously. $23,25,77,81$

A fundamental characteristic of islets is the secretion of hormones to maintain glucose homeostasis. The last phase of hormone secretion, GSIS, other key elements such as GSCa and glucose uptake are crucial for reporting on the overall cellular machinery status, and thus should be systematically coupled to the routinely used GSIS. To assess GSIS, the islets were first incubated with a normal glucose medium and then challenged by a higher concentration. Isolated islets possessed the typical biphasic response with a first spike resulting from predocked insulin granule release, followed by a sustained secretion second phase as described previously. ${ }^{28,82}$ GSIS was stable after 5 days of culture, indicating that the healthy status of cells was maintained. Insulin secretion is tightly regulated by intracellular $\mathrm{Ca}^{2+}, 29,30$ thus GSCa is also an important parameter for evaluating islet function. Similar to GSIS, GSCa presented a biphasic response that was maintained after culture. In fact, voltage-gated $\mathrm{Ca}^{2+}$ channel activation results in the fast elevation of cytosolic $\mathrm{Ca}^{2+}$, followed by slower oscillations mediated by non-selective $\mathrm{Ca}^{2+}$ channels. ${ }^{30}$ In diseased islets from high-fat diet animal models, calcium dynamics are markedly affected with decreased first phase as well as almost-blunted oscillatory response. ${ }^{83}$ Several other models of $\beta$-cell stress show markedly reduced calcium response to glucose, attributed to changes in calcium protein expression, ${ }^{84}$ impaired glucose metabolism, ${ }^{85}$ or abnormal calcium handling. ${ }^{86,87}$ In our experimental conditions, we obtained similar calcium response as previously described in normal animals; ${ }^{83,86}$ the oscillatory phase was stable for 5 days in culture, further confirming the healthy oscillatory profile. Finally, we measured glucose uptake in islets using the fluorescent 2-NBDG to assess the integrity of glucose transporters. 2-NBDG has been described as a surrogate for radiolabeled tracers for measuring glucose uptake in single living cells. ${ }^{36-40}$ In the present study, islets retained intact glucose transport after culture for several days.

To validate the present approach, the most commonly used islet isolation protocol, via CBD injection, was also performed and compared with the present study. Islets isolated using both protocols represented similar phenotypic and functional characteristics.

GSIS relies mostly on $\mathrm{Ca}^{2+}$ entry through voltage-gated $\mathrm{Ca}^{2+}$ channels; however, the pulsatile properties of insulin secretion are highly complex and still poorly understood. A number of ionic conductances, such as that of the TRP family, have been suggested to have a role in $\mathrm{Ca}^{2+}$-mediated insulin secretion. ${ }^{31,32,88-93}$ TRP channels form $\mathrm{Ca}^{2+}$ nonselective channels implicated in various cellular functions. ${ }^{94}$ Therefore, to validate the islet isolation approach of the present study, we sought to assess the implication of the TRPC channel family in insulin secretion. The isolated islets were incubated with different TRPC inhibitors, and 
knockdown of the proteins was performed by siRNAs. When cells were stimulated with high glucose, the presence of TRPC inhibitors not only diminished the first phase of $\mathrm{Ca}^{2+}$ entry and insulin secretion but also the second oscillation phase. This indicates that these channels participate in the depolarization process and activation of the voltage-gated $\mathrm{Ca}^{2+}$ channels as well as the amplification $\mathrm{Ca}^{2+}$ signal afterwards to maintain the insulin secretion. Future studies should further dissect the mechanisms by which these channels participate in the insulin secretion machinery. As such, TRPC channels might represent potential and interesting targets for drug development for diabetes, especially where defects in $\mathrm{Ca}^{2+}$ and insulin oscillations are observed.

In conclusion, in this study we describe an islet isolation protocol that combines functional and phenotypic characterization. This method yields better quality functional islets for use in studying normal and diseased $\beta$-cells. Furthermore, this approach was used to determine new ion channel candidates implicated in insulin secretion.

\section{ACKNOWLEDGMENTS}

This work was supported by the Research Council of the Saint Joseph University_Faculty of Medicine.

\section{DISCLOSURE/CONFLICT OF INTEREST}

The authors declare no conflict of interest.

1. Shapiro AM, Lakey JR, Ryan EA, et al. Islet transplantation in seven patients with type 1 diabetes mellitus using a glucocorticoid- free immunosuppressive regimen. N Engl J Med 2000;343:230-238.

2. O'Neil JJ, Tchipashvili V, Parent RJ, et al. A simple and cost-effective method for the isolation of islets from nonhuman primates. Cell Transplant 2003;12:883-890.

3. Qi $M$, Valiente $L, M c F a d d e n ~ B$, et al. The choice of enzyme for human pancreas digestion is a critical factor for increasing the success of islet isolation. Transplant Direct 2015;1:e14.

4. Jin SM, Lee HS, Oh SH, et al. Adult porcine islet isolation using a ductal preservation method and purification with a density gradient composed of histidine-tryptophan-ketoglutarate solution and iodixanol. Transplant Proc 2014;46:1628-1632.

5. Loganathan G, Graham ML, Spizzo T, et al. Pretreatment of donor pigs with a diet rich in soybean oil increases the yield of isolated islets. Transplant Proc 2014;46:1945-1949.

6. Woolcott OO, Bergman RN, Richey JM, et al. Simplified method to isolate highly pure canine pancreatic islets. Pancreas 2012;41:31-38.

7. Ching $\mathrm{CD}$, Harland $\mathrm{RC}$, Collins $\mathrm{BH}$, et al. A reliable method for isolation of viable porcine islet cells. Arch Surg 2001;136:276-279.

8. Kayton NS, Poffenberger G, Henske J, et al. Human islet preparations distributed for research exhibit a variety of insulin-secretory profiles. Am J Physiol Endocrinol Metab 2015;308:E592-E602.

9. Kitzmann JP, Karatzas T, Mueller KR, et al. Islet preparation purity is overestimated, and less pure fractions have lower post-culture viability before clinical allotransplantation. Transplant Proc 2014;46: 1953-1955.

10. Li DS, Yuan $\mathrm{YH}, \mathrm{Tu} \mathrm{HJ}$, et al. A protocol for islet isolation from mouse pancreas. Nat Protoc 2009;4:1649-1652.

11. O'Dowd JF. The isolation and purification of rodent pancreatic islets of Langerhans. Methods Mol Biol 2009;560:37-42.

12. Shapiro AM, Hao E, Rajotte RV, et al. High yield of rodent islets with intraductal collagenase and stationary digestion-a comparison with standard technique. Cell Transplant 1996;5:631-638.

13. Shewade YM, Umrani M, Bhonde RR. Large-scale isolation of islets by tissue culture of adult mouse pancreas. Transplant Proc 1999;31: $1721-1723$
14. Brunstedt J. Rapid isolation of functionally intact pancreatic islets from mice and rats by Percoll gradient centrifucation. Diabete Metab 1980;6: 87-89.

15. Buitrago A, Gylfe E, Henriksson C, et al. Rapid isolation of pancreatic islets from collagenase digested pancreas by sedimentation through Percol at unit gravity. Biochem Biophys Res Commun 1977;79:823-828.

16. Szot GL, Koudria P, Bluestone JA. Murine pancreatic islet isolation. J Vis Exp 2007; 7:255.

17. Salvalaggio $P R$, Deng $S$, Ariyan $C E$, et al. Islet filtration: a simple and rapid new purification procedure that avoids Ficoll and improves islet mass and function. Transplantation 2002;74:877-879.

18. Banerjee $M$, Otonkoski T. A simple two-step protocol for the purification of human pancreatic beta cells. Diabetologia 2009;52: 621-625.

19. Tons HA, Baranski AG, Terpstra OT, et al. Isolation of the islets of Langerhans from the human pancreas with magnetic retraction. Transplant Proc 2008;40:413-414.

20. Neuman JC, Truchan NA, Joseph JW, et al. A method for mouse pancreatic islet isolation and intracellular CAMP determination. J Vis Exp 2014; 88:e50374.

21. Koh DS, Moody M, Jo J. Collection of islets of Langerhans using an equilibrium method. Biotechniques 2013;55:34-37.

22. Liao YT, Jiang JX, Ye J et al. A novel protocol for mouse islet isolation. Pancreas 2012;41:1134-1135.

23. de Groot M, de Haan BJ, Keizer PP, et al. Rat islet isolation yield and function are donor strain dependent. Lab Anim 2004;38: 200-206.

24. Gotoh M, Maki T, Satomi $S$, et al. Reproducible high yield of rat islets by stationary in vitro digestion following pancreatic ductal or portal venous collagenase injection. Transplantation 1987;43: 725-730.

25. Carter JD, Dula SB, Corbin $\mathrm{KL}$, et al. A practical guide to rodent islet isolation and assessment. Biol Proced Online 2009;11:3-31.

26. Nolan AL. In vitro culture of isolated islets of Langerhans: analysis of function. Methods Mol Biol 2009;560:65-71.

27. Nolan AL, O'Dowd JF. The measurement of insulin secretion from isolated rodent islets of Langerhans. Methods Mol Biol 2009;560: 43-51.

28. Komatsu $M$, Takei $M$, Ishii $\mathrm{H}$, et al. Glucose-stimulated insulin secretion: a newer perspective. J Diabetes Investig 2013;4:511-516.

29. Hiriart M, Aguilar-Bryan L. Channel regulation of glucose sensing in the pancreatic beta-cell. Am J Physiol Endocrinol Metab 2008;295: E1298-E1306.

30. Rorsman P, Braun M. Regulation of insulin secretion in human pancreatic islets. Annu Rev Physiol 2013;75:155-179.

31. Colsoul B, Vennekens R, Nilius B. Transient receptor potential cation channels in pancreatic beta cells. Rev Physiol Biochem Pharmacol 2011;161:87-110.

32. Sabourin J, Le Gal L, Saurwein L, et al. Store-operated $\mathrm{Ca}^{2+}$ entry mediated by Orai1 and TRPC1 participates to insulin secretion in rat beta-cells. J Biol Chem 2015;290:30530-30539.

33. Santulli G, Pagano G, Sardu C, et al. Calcium release channel RyR2 regulates insulin release and glucose homeostasis. J Clin Invest 2015;125:1968-1978.

34. Gustafsson AJ, Ingelman-Sundberg $H$, Dzabic $M$, et al. Ryanodine receptor-operated activation of TRP-like channels can trigger critical $\mathrm{Ca}^{2+}$ signaling events in pancreatic beta-cells. FASEB J 2005;19: 301-303.

35. Kenty JH, Melton DA. Testing pancreatic islet function at the single cell level by calcium influx with associated marker expression. PLoS One 2015:10:e0122044.

36. Lloyd $P G$, Hardin CD, Sturek M. Examining glucose transport in single vascular smooth muscle cells with a fluorescent glucose analog. Physiol Res 1999;48:401-410.

37. Zou C, Wang Y, Shen Z. 2-NBDG as a fluorescent indicator for direct glucose uptake measurement. J Biochem Biophys Methods 2005;64: 207-215.

38. Ohtsubo K, Chen MZ, Olefsky JM, et al. Pathway to diabetes through attenuation of pancreatic beta cell glycosylation and glucose transport. Nat Med 2011;17:1067-1075.

39. Yamada K, Nakata M, Horimoto $\mathrm{N}$, et al. Measurement of glucose uptake and intracellular calcium concentration in single, living pancreatic beta-cells. J Biol Chem 2000;275:22278-22283. 
40. Yamada $\mathrm{K}$, Saito $\mathrm{M}$, Matsuoka $\mathrm{H}$, et al. A real-time method of imaging glucose uptake in single, living mammalian cells. Nat Protoc 2007;2: 753-762.

41. Thomas D, Tovey SC, Collins TJ, et al. A comparison of fluorescent $\mathrm{Ca}^{2+}$ indicator properties and their use in measuring elementary and global $\mathrm{Ca}^{2+}$ signals. Cell Calcium 2000;28:213-223.

42. Hagen BM, Boyman L, Kao JP, et al. A comparative assessment of Fluo $\mathrm{Ca}^{2+}$ indicators in rat ventricular myocytes. Cell Calcium 2012;52: 170-181.

43. Grynkiewicz G, Poenie M, Tsien RY. A new generation of $\mathrm{Ca}^{2+}$ indicators with greatly improved fluorescence properties. J Biol Chem 1985;260:3440-3450.

44. Valdeolmillos $M$, Santos RM, Contreras D, et al. Glucose-induced oscillations of intracellular $\mathrm{Ca}^{2+}$ concentration resembling bursting electrical activity in single mouse islets of Langerhans. FEBS Lett 1989;259:19-23.

45. Niclauss N, Meier R, Bedat B, et al. Beta-cell replacement: pancreas and islet cell transplantation. Endocr Dev 2016;31:146-162.

46. Markmann JF. Isolated pancreatic islet transplantation: a coming of age. Am J Transplant 2016;16:381-382.

47. Farney AC, Sutherland DE, Opara EC. Evolution of islet transplantation for the last 30 years. Pancreas 2016;45:8-20.

48. Brennan DC, Kopetskie HA, Sayre $\mathrm{PH}$, et al. Long-term follow-up of the edmonton protocol of islet transplantation in the United States. Am J Transplant 2016;16:509-517.

49. Andrades $\mathrm{P}$, Asiedu $\mathrm{C}$, Ray $\mathrm{P}$, et al. Islet yield after different methods of pancreatic Liberase delivery. Transplant Proc 2007;39:183-184.

50. Brandhorst $\mathrm{H}$, Friberg $\mathrm{A}$, Andersson $\mathrm{HH}$, et al. The importance of tryptic-like activity in purified enzyme blends for efficient islet isolation. Transplantation 2009;87:370-375.

51. Yesil P, Michel M, Chwalek K, et al. A new collagenase blend increases the number of islets isolated from mouse pancreas. Islets 2009;1: 185-190.

52. Fujio A, Murayama K, Yamagata $Y$, et al. Collagenase $H$ is crucial for isolation of rat pancreatic islets. Cell Transplant 2014;23:1187-1198.

53. Li F, Jiang X, Li Y, et al. Isolation of mouse islet by collagenase perfusion through the splenic vein. Transplantation 2013;96:e88-e89.

54. Shibata A, Ludvigsen Jr CW, Naber SP, et al. Standardization fo a digestion-filtration method for isolation of pancreatic islets. Diabetes 1976;25:667-672

55. McCall MD, Maciver AH, Pawlick $\mathrm{R}$, et al. Histopaque provides optimal mouse islet purification kinetics: comparison study with Ficoll, iodixanol and dextran. Islets 2011;3:144-149.

56. Kopska T, Furstova V, Kovar J. Modified method for isolation of langerhans islets from mice. Transplant Proc 2008;40:3611-3614.

57. Delle $\mathrm{H}$, Saito $\mathrm{MH}$, Yoshimoto $\mathrm{PM}$, et al. The use of iodixanol for the purification of rat pancreatic islets. Transplant Proc 2007;39: 467-469.

58. van der Burg MP, Basir I, Bouwman E. No porcine islet loss during density gradient purification in a novel iodixanol in University of Wisconsin solution. Transplant Proc 1998;30:362-363.

59. Andersson A. Isolated mouse pancreatic islets in culture: effects of serum and different culture media on the insulin production of the islets. Diabetologia 1978;14:397-404.

60. Kessler $L$, Jesser $C$, Belcourt $A$, et al. Influence of acinar tissue contamination on encapsulated pancreatic islets: morphological and functional studies. Transplantation 1997:63:1537-1540.

61. Morini S, Braun M, Onori $\mathrm{P}$, et al. Morphological changes of isolated rat pancreatic islets: a structural, ultrastructural and morphometric study. J Anat 2006;209:381-392.

62. Abdelli S, Abderrahmani A, Hering BJ, et al. The c-Jun N-terminal kinase JNK participates in cytokine- and isolation stress-induced rat pancreatic islet apoptosis. Diabetologia 2007;50:1660-1669.

63. Abdelli S, Ansite J, Roduit R, et al. Intracellular stress signaling pathways activated during human islet preparation and following acute cytokine exposure. Diabetes 2004;53:2815-2823.

64. Janjic D, Wollheim CB. Islet cell metabolism is reflected by the MTT (tetrazolium) colorimetric assay. Diabetologia 1992;35:482-485.

65. Khadija S, Veluthakal R, Sidarala V, et al. Glucotoxic and diabetic conditions induce caspase 6-mediated degradation of nuclear lamin A in human islets, rodent islets and INS-1 832/13 cells. Apoptosis 2014;19:1691-1701.
66. Hui H, Dotta F, Di Mario $U$, et al. Role of caspases in the regulation of apoptotic pancreatic islet beta-cells death. J Cell Physiol 2004;200: 177-200.

67. Yamada K, Ichikawa F, Ishiyama-Shigemoto S, et al. Essential role of caspase-3 in apoptosis of mouse beta-cells transfected with human Fas. Diabetes 1999:48:478-483.

68. Maedler K, Spinas GA, Lehmann R, et al. Glucose induces beta-cell apoptosis via upregulation of the Fas receptor in human islets. Diabetes 2001;50:1683-1690.

69. Kim WH, Lee JW, Suh $\mathrm{YH}$, et al. Exposure to chronic high glucose induces beta-cell apoptosis through decreased interaction of glucokinase with mitochondria: downregulation of glucokinase in pancreatic beta-cells. Diabetes 2005;54:2602-2611.

70. Thomas D, Yang H, Boffa DJ, et al. Proapoptotic Bax is hyperexpressed in isolated human islets compared with antiapoptotic Bcl-2. Transplantation 2002;74:1489-1496.

71. Federici M, Hribal M, Perego $L$, et al. High glucose causes apoptosis in cultured human pancreatic islets of Langerhans: a potential role for regulation of specific $\mathrm{Bcl}$ family genes toward an apoptotic cell death program. Diabetes 2001;50:1290-1301.

72. McKenzie MD, Jamieson E, Jansen ES, et al. Glucose induces pancreatic islet cell apoptosis that requires the $\mathrm{BH} 3$-only proteins Bim and Puma and multi-BH domain protein Bax. Diabetes 2010;59: 644-652.

73. Johnson JD, Ahmed NT, Luciani DS, et al. Increased islet apoptosis in Pdx1+/ - mice. J Clin Invest 2003;111:1147-1160.

74. Garcia-Ocana A, Takane KK, Syed MA, et al. Hepatocyte growth factor overexpression in the islet of transgenic mice increases beta cell proliferation, enhances islet mass, and induces mild hypoglycemia. J Biol Chem 2000;275:1226-1232.

75. Bock T, Pakkenberg B, Buschard K. Genetic background determines the size and structure of the endocrine pancreas. Diabetes 2005;54: 133-137.

76. Nagaraju S, Bottino R, Wijkstrom M, et al. Islet xenotransplantation: what is the optimal age of the islet-source pig? Xenotransplantation 2015;22:7-19.

77. Inuwa IM, El Mardi AS. Correlation between volume fraction and volume-weighted mean volume, and between total number and total mass of islets in post-weaning and young Wistar rats. J Anat 2005;206: 185-192.

78. Perfetti R, Rafizadeh CM, Liotta AS, et al. Age-dependent reduction in insulin secretion and insulin mRNA in isolated islets from rats. Am J Physiol 1995;269(Part 1):E983-E990.

79. Lamb M, Laugenour K, Liang $\mathrm{O}$, et al. In vitro maturation of viable islets from partially digested young pig pancreas. Cell Transplant 2014;23: 263-272.

80. Maedler K, Schumann DM, Schulthess F, et al. Aging correlates with decreased beta-cell proliferative capacity and enhanced sensitivity to apoptosis: a potential role for Fas and pancreatic duodenal homeobox-1. Diabetes 2006;55:2455-2462.

81. de Haan BJ, Faas MM, Spijker $\mathrm{H}$, et al. Factors influencing isolation of functional pancreatic rat islets. Pancreas 2004;29:e15-e22.

82. Olofsson CS, Gopel SO, Barg S, et al. Fast insulin secretion reflects exocytosis of docked granules in mouse pancreatic B-cells. Pflugers Arch 2002:444:43-51.

83. Chen $\mathrm{C}$, Chmelova $\mathrm{H}$, Cohrs CM, et al. Alterations in beta-cell calcium dynamics and efficacy outweigh islet mass adaptation in compensation of insulin resistance and prediabetes onset. Diabetes 2016;65: 2676-2685.

84. Roe MW, Worley 3rd JF , Tokuyama Y, et al. NIDDM is associated with loss of pancreatic beta-cell L-type $\mathrm{Ca}^{2+}$ channel activity. Am J Physiol 1996;270(Part 1):E133-E140.

85. Kato $\mathrm{S}$, Ishida $\mathrm{H}$, Tsuura $\mathrm{Y}$, et al. Alterations in basal and glucosestimulated voltage-dependent $\mathrm{Ca}^{2+}$ channel activities in pancreatic beta cells of non-insulin-dependent diabetes mellitus GK rats. J Clin Invest 1996;97:2417-2425.

86. Do OH, Low JT, Gaisano HY, et al. The secretory deficit in islets from $\mathrm{db} / \mathrm{db}$ mice is mainly due to a loss of responding beta cells. Diabetologia 2014;57:1400-1409.

87. Marie JC, Bailbe D, Gylfe E, et al. Defective glucose-dependent cytosolic $\mathrm{Ca}^{2+}$ handling in islets of GK and nSTZ rat models of type 2 diabetes. J Endocrinol 2001;169:169-176. 
88. Yamada $\mathrm{H}$, Yoshida $\mathrm{M}$, Ito $\mathrm{K}$, et al. Potentiation of glucose-stimulated insulin secretion by the GPR40-PLC-TRPC pathway in pancreatic beta-cells. Sci Rep 2016;6:25912.

89. Marabita F, Islam MS. Expression of transient receptor potential channels in the purified human pancreatic beta-cells. Pancreas 2016; e-pub ahead of print.

90. Shigeto M, Ramracheya R, Tarasov Al, et al. GLP-1 stimulates insulin secretion by PKC-dependent TRPM4 and TRPM5 activation. J Clin Invest 2015;125:4714-4728.
91. Colsoul B, Schraenen A, Lemaire K, et al. Loss of high-frequency glucoseinduced $\mathrm{Ca}^{2+}$ oscillations in pancreatic islets correlates with impaired glucose tolerance in Trpm - / - mice. Proc Natl Acad Sci USA 2010;107:5208-5213.

92. Brixel LR, Monteilh-Zoller MK, Ingenbrandt CS, et al. TRPM5 regulates glucose-stimulated insulin secretion. Pflugers Arch 2010;460:69-76.

93. Cheng $H$, Beck $A$, Launay $P$, et al. TRPM4 controls insulin secretion in pancreatic beta-cells. Cell Calcium 2007;41:51-61.

94. Abramowitz J, Birnbaumer L. Physiology and pathophysiology of canonical transient receptor potential channels. FASEB J 2009;23:297-328. 